months in some of the largest hospitals in this country, representing 80,000 in-patients and several hundred thousand out-patients, Mayo Robson) that I have ventured to relate these two cases to you. Both of them are interesting, the first in being complicated with cystitis and a general debilitated condition which rendered diagnosis almost impossible; the second in the absence of symptoms until obstruction occurred, and in the rapid and favourable termination of the case. In neither case was there a history of jaundice or colic, and no attack of a similar nature had previously occurred. In the majority of the cases collected by Naunyn undoubted symptoms of cholelithiasis had been present at an earlier period, and of these colic seems to have been the most common. The unfacetted condition of the stones in my cases shows them to have been single, and their size, in my opinion, quite precluded their being passed by the cystic and common ducts, although one the size of a hen's egg has been reported by Rokitansky as having escaped by this route.

In the second case no indication whatever of any hepatic disturbance existed, and until symptoms of obstruction occurred the patient was quite well. In the first case, however, the indigestion, tenderness, and enlargement of the liver, rigor, and rise of temperature with profuse sweating, suggested liver disturbance, but in the presence of severe cystitis and the absence of more definite symptoms and history, this was thrown out of court. While under Dr. Griffiths's care a localised swelling in the right hypochondrium was felt, but this completely disappeared. Neither hæmorrhage nor tympanites was present in either case at any time.

From the size of the stones in these cases it is evident that they must have ulcerated into the bowel and produced a gastro-intestinal fistula. As you will see from the table before you, which is taken from Naunyn's Treatise on Cholelithiasis, ${ }^{1}$ gastro-duodenal fistulæ are the most common, and both of my cases were of this kind. The first was proved to be so by post-mortem examination, and the sudden onset of the symptoms and the character of the vomit leave me in little doubt about the second. The probable explanation of this increased liability of the duodenum to be affected in this way is its close proximity to the body of the gall bladder, and its comparative immobility.

As in other cases of a similar kind, the character of the vomit was a striking feature. Indeed, in the second case this was the main diagnostic symptom. In both instances it was copious and almost like pure bile, but towards the end in the first case it became slightly stercoraceous. This is quite in accord with the position in which the calculus was found after death. In the cases in which the stone is impacted in the duodenum, the vomit is not fæculent, and the symptoms come on rapidiy. This seems to have been what occurred in the second case. On the other hand, when impaction occurs lower down in the gut, vomiting appears late, and almost from the first assumes a fæculent character. In Case II the shape of the gall stone is well adapted for its rapid passage along the intestinal canal, and this in reality occurred. In Case I, on the other hand, the stone is of a more rounded form, and its smallest diameter is greater than in the second case, and consequently liability to impaction is increased. In contradistinction to the seat of biliary intestinal fistulæ, the place of impaction of gall stones in the bowel is mainly the ileum. This is probably due to the fact that the small intestine gradually narrows as it passes downwards, and the tendency to obstruction therefore increases.

In neither of the two cases was the pain of exceptionally severe character. In the first case the patient felt a peculiar weakness come over him, probably about the time the calculus entered the duodenum. Other points of interest in these cases are the duration of the obstruction, the sex, and the age of the patients. Both patients were 60 , a time of life at which gall stones are relatively common. According to Schüller's table intestinal obstruction from this cause is most frequent between the ages of 50 and 70 , but when one calculates the number of cases at any age relative to the number of persons living at that age one finds that the frequency of impaction gradually increases with the age of the patient. As regards sex, women are much more frequently affected than men. In Schüller's ${ }^{2} 139$ cases only 25.9 per cent. occurred in men. My own cases were equally divided, one was a man, the other a woman. The symptoms of obstruction also lasted the usual length of time From the table I show you, also taken from Naunyn, you will see that in nearly all the cases the duration of the symptoms was from two to ten days. In my fatal case the symptoms lasted ten days, in the one which recovered two days, although, on account of the constipation (perhaps in part due to the morphine), the stone was not voided until three days later.

The mortality in these cases is considerable. In Schüller's and Dufort's cases it was 56 per cent., in Courvoisier's 44 per cent-in all 50 per cent. Even operation has not reduced the fatalities. Out of 23 cases collected by Naunyn 16 died, and he states that surgical procedures are not to be generally recommended. Treated medicinally 50 per cent. recover, but doubtless the high mortality after operation is due to this having been undertaken with the patient in a very weak condition. Each case should be treated on its merits. Recovery may occur after the symptoms have existed a week or longer (in one case, Dr. Omond's, ${ }^{3}$ after stercoraceons vomiting had lasted upwards of three weeks) but it is doubtful whether it is wise to wait longer than a week, as usually the patient rapidly gets weaker, and his power of recovery from operative measures less.

As regards the recurrence of attacks in cases terminating favourably, authorities differ. Naunyn says that true relapses are extremely rare, and he has only been able to find one undoubted case of this kind. Brockbank, on the other hand, states that " patients occasionally recover from one attack of intestinal obstruction only to undergo another, or even two or three more attacks, each brought on by the passage of large gall stones through the small intestine and the ileocæcal valve." My own case has remained perfectly well since her recovery from the attack, and it is probable that the fistula has healed.

With regard to gall-bladder colon fistulæ, Mr. Mayo Robson ${ }^{4}$ could only find two specimens in the London museums. I believe Dr. Griffiths will show you one from our museum.

$$
\text { REFERENCES. }
$$

1 New Sydenham Society, i896, p. 143. 2 Schüller, Gallensteine als Ursache der Darmobstruction. Doctor-Dissertation, Strassburg, 1891. 3 Quoted by Murchison, Diseases of the Liver, and edition, p. 494. 3 BRITISH MEDICAL JOURNAL, vol. i, 1897 .

\section{NOTE ON THE TREATMENT OF RELAPSING ACNE.}

By LESLIE PHILLIPS, M.D.,

Surgeon, Birmingham Hospital for Skin and Urinary Diseases.

IT may be postulated that all cases of acne are curable, but an indispensable factor in the cure of many cases is perseverance. The disease may be so inveterate, so disfiguring, so relapsing, so intractable, that cure can only be effected by continuous treatment, extending, it may be, over a year or more. So long as a case continues to improve there is no difficulty in getting the patient to persevere. In chronic cases (I mean chronic in the sense that the papules are indolent, for cases may be chronic in the sense of long-lasting, although the individual lesions are acute or subacute), the results of ordinary treatment are such as to induce continuance. The difficulty lies with the subacute or relapsing cases, and in these the almost invariable reason for the want of the necessary perseverance is the discouragement of both medical man and patient which results if, not,withstanding the faithful observance of directions, fresh acne lesions constantly continue to erupt. Here it is not unlikely that most attempts to use radically curative local applications (containing, for example, sulphur) only aggravate the disease and exhaust the patience which it is a needful part of the scheme of treatment to cultivate.

As is well known in such circumstances, the indication is to subdue this tendency to fresh eruption by soothing the skin and diminishing hyperæmia. The routine method of doing this is by the calamine or zinc lotion of the hospital pharmacopœias, but the tendency of fresh spots to erupt is often so marked that disappointment not infrequently results, and I have known an instance in which such a lotion containing a drachm of glycerine to the ounce acted as an irri- 
tant, while when the quantity of this ingredient was reduced to Io minims the desired soothing effect was obtained. This example will show the scrupulous ( ar 3 which may be needful in directing the treatment of obstinately relapsing examples of acne, a care which needs to be exercised not only with regard to prescribed remedies, but also with regard to local régime.

There is more need for emphasising this principle of subduing irritation at the present day when so much attention is rivetted upon the microbic origin of dermatoses (including acne), for the effect of such views is to exaggerate the importance of bactericidal medication, which too often means the employment of irritating substances. The practical impossibility of sterilising large tracts of skin, especially when its sebaceous glands are distended with deep-lying cultures, ought to warn us that treatment having such an object has but a slender scientific basis to rest upon. More trust should be reposed in the resisting power of normal uninflamed skin to render bacteria impotent.

I have at present under my care a skin case which forcibly illustrates the practical value of the indication to subdue inflammation. A young woman has an inflamed patch occupying a considerable area on and around the leg, which is the seat of constantly recurring, large, deep, painful, phlyzaceous pustulation. The difficulty of dealing with this case will be understood when it is stated that in spite of confinement to bed extending over months, and in spite of the most diverse treatment in which I have had the advantage of the views of my colleagues, the disease remained unbenefited and unsubdued until repeated leeching and high elevation of the limb gradually reduced the chronic inflammation of the derma. Then pustules diminished and ceased to appear. It is not that pus-forming cocci ceased to be present in the glands, follicles, and lymph spaces of the skin, but that they are comparatively impotent for mischief when this approximates the normal; while their power is great in the presence of stasis. The attempt to antisepticise the skin by the application of even such a mild antiseptic as a boric acid fomentation aggravated the condition when congestion was present, while directly the congestion was relieved by mechanical means alone the skin asserted its power to deal with the mischief unassisted by any such agent as would comply with the view that it was necessary to employ chemical agents for the destruction of pathogenic cocci.

The method which I find of value in securing the necessary calmative action in the type of acne referred to is as follows: First and foremost no scap is to be used, no matter of what kind, how "pure," or how highly recommended by the medical profession for the complexion. It does not matter that soap appears to be indicated by the greasy appearance of the skin often present in cases of acne; the greasiness is better dealt with by other means. Soap is a skin stimulant or irritant, and its use is entirely out of harmony with a sedative treatment. The use or omission of soap will often determine bad or good results in the treatment of acutely erupting or inflamed acne. The "vigorous scrubbing with soap and flannel," the "frequent and energetic washing with soft soap and flannel" recommended by some writers on acne, if necessary at all, which I very much doubt, are entirely out of place in dealing with anything but the most indolent examples of the disease.

The second item in my method of locally dealing with such cases is entirely to discard lotions, ointments, and pastes and to substitute a dusting powder. The temptation here is not small to depart somewhat from the immediate subject of the paper to point out arguments defending the common use of face powders in a climate like ours, and to ridicule much of what is written in reprobation of the practice, but this parenthetic reference to the matter must suffice.

With regard to the composition of the dusting powder, any of the usual formulæ may be employed. Recently I have used Southall's dimatos as a basis. This earth is a Kieselguhr, consisting of almost pure silica, and is extraordinarily absorbent. Unless much diluted with starch it is, however, better gently rubbed into the skin than dusted on, for owing to its flocculent character it adheres better to the surface when smoothly rubbed on. Equal parts of pusol and dimatos form a powder of considerable curative value in the kind of acne cases under consideration, and for most cases is the proper strength to use, although occasionally a case is met with in which the skin is so delicate and sensitive that less pusol must be used. The use of powders has the advantage that treatment may be continued through the day as well as by night; for a little powder, the excess of which has been lightly brushed off, is practically invisible. This particular formula effectively removes greasiness from the skin, and improves its general sheen and appearance, while the influence exerted by it on relapsing acne is distinct. In a week or two the disease will be sufficiently quiescent to justify more stimulative therapeutic measures. Here any of the usual sulphur ointments may be employed, but the application should be at first cautious and at intervals only. In most cases a nightly rubbing with a strong sulphur ointment is undesirable, twice a week is better. I now use almost exclusively an ointment containing pusol 3 jss, paraf. mol. $3 j$. This is rubbed in at night, while the face is dressed with the above-mentioned powder in the day time. Together these two prescriptions constitute a cleanly way of treating relapsing acne, and unless the treatment ordered is agreeable to use we may be sure that it will not be continued by the patient with that persistence which is essential to success in dealing with a chronic affection like acne.

\section{SOME EXPERIMENTS ON THE SOLUBILITY OF GALL STONES IN OILS. BY LINDLEY S(YOTT, M.A., M.D., London.}

IT would seem advisable to place on record the following experiments respecting the solvent power of various oils on gall stones. Beakers containing from 20 to $50 \mathrm{c.cm}$. of oil, the quantity varying according to the size of the stone used in the experiment, were kept in a warm chamber at $98.4^{\circ} \mathrm{F}$. The stones were immersed in the oils, removed from time to time, gently dried with filter paper, and weighed. The oils employed were pure olive oil, pure almond oil, and the odourless and tasteless purified petroleum oil known as paroleine.

The stones used in the first experiment were passed by a patient in whom the olive-oil treatment had been tried with some success. They were about the size of a dried green pea, facetted, friable, and dark greenish-brown in colour. As they dissolved they showed a thin outer brownish layer of pigment, a thick middle layer light yellow in colour, consisting largely of cholesterine, and a small dark nucleus of pigment. They dissolved with about equal readiness in the different oils, losing approximately one quarter of their weight in twelve hours, one-half in twenty-four hours, and threequarters in forty-eight hours. After thirty-six hours' immersion little was left but the nucleus.

EXPERIMENT I.

\begin{tabular}{|c|c|c|c|c|c|c|c|c|c|}
\hline \multirow{2}{*}{$\begin{array}{c}\text { Time of } \\
\text { Immer- } \\
\text { sion } \\
\text { in } \\
\text { Oil. }\end{array}$} & \multicolumn{3}{|c|}{$\begin{array}{l}\text { Olive Oil. } \\
\text { Weight of Stone, } \\
0.855 \mathrm{~g} .\end{array}$} & \multicolumn{3}{|c|}{$\begin{array}{l}\text { Almond Oil. } \\
\text { Weight of Stone, } \\
0.08 \mathrm{~g} \text {. }\end{array}$} & \multicolumn{3}{|c|}{$\begin{array}{l}\text { Paroleine. } \\
\text { Weight of Stone, } \\
0.072 \mathrm{~g} .\end{array}$} \\
\hline & 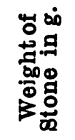 & 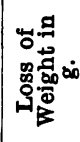 & 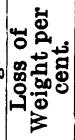 & 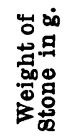 & 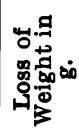 & 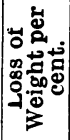 & 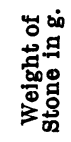 & 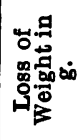 & 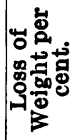 \\
\hline 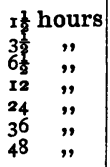 & $\begin{array}{l}0.0850 \\
0.0810 \\
0.0759 \\
0.0633 \\
0.0460 \\
0.0310 \\
0.0230\end{array}$ & $\begin{array}{l}0.0005 \\
0.0045 \\
0.0105 \\
0.0220 \\
0.0395 \\
0.0540 \\
0.0625\end{array}$ & $\begin{array}{r}058 \\
5.26 \\
12.20 \\
2590 \\
53.70 \\
67.50 \\
75.00\end{array}$ & $\begin{array}{l}0.078 \\
0.074 \\
0.068 \\
0.056 \\
0.037 \\
0.026 \\
0.020\end{array}$ & $\begin{array}{l}0.002 \\
0.006 \\
0.012 \\
0.024 \\
0.043 \\
0.054 \\
0000\end{array}$ & $\begin{array}{r}2.5 \\
7.5 \\
150 \\
240 \\
53.7 \\
67.5 \\
75.0\end{array}$ & $\begin{array}{l}0.071 \\
c .068 \\
0.063 \\
0.054 \\
0.038 \\
0.025 \\
0.019\end{array}$ & $\begin{array}{l}0.001 \\
0.004 \\
0.009 \\
0.018 \\
0.034 \\
0.047 \\
0.053\end{array}$ & $\begin{array}{r}1.5 \\
5.5 \\
12.5 \\
24.9 \\
47.2 \\
65.2 \\
73.6\end{array}$ \\
\hline
\end{tabular}

The stones used in Experiment II were removed from the gall bladder by operation. They were considerably greater in bulk than those of the previous experiment being somewhat larger than cherry stones. They were hard in substance, and appeared to dissolve uniformly, maintaining their original brownish-yellow colour. As they went into golution they showed no well-defined layers such as were 